\title{
LAS DOS DONCELLAS: NOVELIZACIÓN DE FORMAS Y SENTIDOS MÚLTIPLES
}

A. Organización de la materia nOvelesca

\section{Novela in medias res}

Lo que indudablemente se percibe leyendo Las novelas ejemplares cervantinas no es una simple reflexión de la vida, sino más bien la vida refractada mediante la poetización. No es que se trate de resolver lo paradojico de la existencia humana o un aspecto de ésta en cada una de dichas novelitas, sino de presentar la vida artísticamente -a veces en forma más inclusiva que en otras- y en toda su vitalidad, de la cual lo ideal y el idealismo, lo real y el realismo tomados individualmente son sólo fragmentos de la vida humana. Y, así como podemos observar matices de blancura, lo colosal de la conciencia creadora de Cervantes ha sido poetizar lo real, lo posible, lo probable - una multiplicidad de realidades históricas y arquetípicas-, haciendo uso en cada transposición artística de una serie de procedimientos en diversos niveles de concreción. Así ocurre con la técnica in medias res, la cual se percibe en $E l$ casamiento engañoso, el Coloquio de los perros, La señora Comelia, El amante liberal, La fuerza de la sangre y Las dos doncellas, y no sólo en las dos últimas como parece sugerir Díaz-Plaja ${ }^{1}$.

1 Guturrmo Dinz-PLnA, «La técnica narrativa de Cervantes*, Revista de Filología Espantola, XXXII, 1948, p. 244: «Dentro de las Novelas ejemplares que clasifico en el grupo caracterizado por una dinámica en el tiempo, pueden anotarse dos subgrupos: I. Novelas cuya acción central comienza "ex abrupto". El narrador nos sitta in medias res con un episodio que es, a la vez, comienzo y clave. Asi, el 
¿Y cómo crea Cervantes la ilusión de los varios niveles narrativos in medias res? Para responder esta pregunta basta contrastar el comienzo de tres novelas, empezando por El amante liberal. Esta obra comienza con el desgarrado monólogo de Ricardo en cautiverio, un lamento, que por su tono, nos recuerda el monólogo de Segismundo de La vida es sueño. Cervantes compara, con el soliloquio de Ricardo, «las lamentables ruinas de la desdichada Nicosia" con el lamentable estado emocional de su protagonista. El monólogo de Ricardo presupone el rechazo del amor instintivo de Ricardo hacia Leonisa y la captura de aquél por los corsarios turcos. Algo distinto ocurre, en cambio, en El casamiento engañoso y Las dos doncellas, cuyos temas centrales se desprenden también de sucesos anteriores a los relatos de los personajes principales. En El casamiento engañoso tenemos el matrimonio por mutuo engaño; y en Las dos doncellas está la pérdida de la virginidad y de la reputación de Teodosia y la pérdida de la reputación de Leocadia, debido a las promesas matrimoniales por parte de Marco Antonio hacia Teodosia y a las falsas esperanzas connubiales que éste infunde en Leocadia. Contrario a El amante liberal, estas novelas no empiezan con un monólogo. En El casamiento engañoso, cuya acción se abre con la palabra «salía", primer vocablo de la novela, lo que vemos de inmediato es la salida de Campuzano del hospital de la Resurrección, después de su matrimonio por mutuo engaño y de haber sudado las catorce bubas incurridas de su consorte nupcial: doña Estefanía. Si bien la acción se origina con el primer término, Cervantes ha insertado una humorística descripción del estado físico de Campuzano y su plática con su amigo Peralta antes del relato de aquél acerca de su casamiento engañoso. Esto equivale a decir que tal descripción y el diálogo de los dos amigos, ajenos al relato del matrimonio desafortunado de Campuzano, sirven para

rapto de Leocadia al comenzar La fuerza de la sangre; o la irrupción de Teodosia en la venta al empezar las dos doncellas». RUTH El SAFFAR y RODRiguez-Luis, por su parte, afirman algo diferente que Díaz-Plaja: para El Saffar, Novel to Romance: A study of Cervantes's Novelas ejemplares (The John's Hopkins University Press, Baltimore and London, 1974), las novelas que empiezan in medias res son Las dos doncellas (ibíd., p. 109), La señora Comelia (ibid., p. 119) y El amante liberal (ibíd., p. 149), mientras que Julio Rodriguez-Luis (Estructura y personaje en el arte narrativo de las «Novelas ejemplares*), Unpublished Ph. D. dissertation. Princeton University, 1965, asevera que ade todas las Novelas (ejemplares), la del Amante liberal es la que con más propiedad puede llamarse que comienza in medias res, pues en El casamiento engañoso, el encuentro de los dos amigos es en realidad independiente de la historia que luego cuenta uno de ellos, y en Las dos doncellas, que es el otro caso que podria citarse, la acción no ha avanzado tanto al encontrarse los dos hermanos como para que lo que cuenta la primera doncella sea otra cosa que necesaria relación de lo que la ha llevado hasta donde se encuentran entonces» (p. 110). 
posponer el cuento de éste, el cual podría estar al comienzo de la novela.

Lo que posterga la información de los hechos anteriores a la narración principal en Las dos doncellas es la descripción de los pormenores de la llegada tanto de Teodosia como de don Rafael a un mesón de Castilblanco. En realidad, el soliloquio de Teodosia, con el que debería empezar la obra y por el que empezamos a conocer el fraude de Marco Antonio que causó la situación lamentable de Teodosia, lo encontramos muy entrada ya la narración. Es decir, si midiéramos el espacio textual entre el principio de la novela y el cuento de los hechos ocurridos anteriores a la narración principal, el espacio textual es mayor o más amplio en Las dos doncellas que en El casamiento engañoso. Por otro lado, a diferencia de El casamiento engañoso, la acción en Las dos doncellas no se inicia con la primera palabra de la novela, sino después de introducirse, de una forma imprecisa, el primer escenario en que los hechos del relato principal acontecen: «cinco leguas de la ciudad de Sevilla, está un lugar que se llama Castilblanco, y en una de muchos mesones que tiene (es decir sin identificar cuál venta), a la hora que anochecía entró un caminante sobre un hermoso cuárago extranjero» (p. 1119) ${ }^{2}$. En otras palabras, y merece apuntarlo aquí, Cervantes roza puntos comunes en las novelas in medias res, al mismo tiempo que individualiza las novelitas para diferenciarlas y sondear profundamente no sólo «el problema de lo concreto y lo ideal en la belleza" ${ }^{3}$, en el amor y la complejidad del alma humana, sino también en cómo se presentan tales temas. Así tenemos que en El casamiento engañoso los hechos anteriores a la narración en presente vendrían a ser el amor instintivo de Campuzano, lo que recuerda el amor instintivo de Ricardo hacia Leonisa en El amante liberal. Lo peculiar de Campuzano, sin embargo, es que está infestado de lascivia y del amor a los bienes materiales (rasgo materialista que doña Estefanía decía tener) y que son elementos que sirven para distinguirle del amor de Ricardo. Por otra parte, las mentiras o tretas de Campuzano valdrían para ponernos en contacto con las promesas falsas de Marco Antonio en Las dos doncellas, aunque hechas por diferentes motivos en cada caso. Todo esto simplemente significa que, primero, la capacidad poética de Cervantes trata de penetrar tanto en la técnica como en los temas, los cuales vie-

2 Las citas sobre Las dos doncellas y otras obras de Cervantes en este estudio y en las notas vienen de ANGel. Valbunea Prat, Miguel de Cenvantes Saavedra: Obras completas, t. I y t. II. Madrid, Aguilar, 1970. Estas citas vendrán entre paréntesis, con la letra p. y el número de la página.

3 Helmut Hatzfeld, Estudios sobre el Barroco, tr. del alemán por Carlos Claverfa. Madrid, Editorial Gredos, 1964, p. 393. 
nen a ser literaturizados por aquélla y no al revés; y, segundo, que si uno quisiera analizar los varios procedimientos empleados en Las novelas ejemplares, se encontrana la creación de tales arbitrios en varios grados de existencia, tal como ocurre en sus novelas cuyas estructuras empiezan de una forma desigual in medias res.

\section{Partes de la materia novelesca}

Según Casalduero, «la materia novelesca (de Las dos doncellas) se organiza en cuatro partes. Dos ventas, una en Andalucía, cerca de Sevilla, y la otra en Cataluña, cerca de Barcelona; la estancia en la casa de don Sancho de Cardona; y por último en Andalucía otra vez» ${ }^{4}$. Con tal afirmación se piensa que se ofrece el elemento espacial como base formal de la obra, haciendo sobresalir sólo los lugares más inclusivos, es decir, sin tener en cuenta los sitios menores en que la acción viene distribuida. Como puede observarse, $\mathrm{Ca}$ salduero indica dos regiones españolas -Andalucía y Cataluña-, pero sucede que la casa de don Sancho de Cardona está situada en Barcelona, ciudad que está también en Cataluña, lo que, siguiendo el parecer de este comentarista cervantino, nos llevaría a concluir que «la materia novelesca» de Las dos doncellas no está organizada en cuatro partes sino en tres: Andalucía, Cataluña y Andalucía. Es más, si se tiene en cuenta el decurso de la acción, uno se encuentra con un escenario múltiple: primero, una venta de Castilblanco, a cinco leguas de Sevilla, en donde se revelan las identidades de Teodosia y de don Rafael y en la cual la acción se reparte entre la alcoba y fuera de ella, e inclusive en la casa de los vecinos: «fuéronse los vecinos a sus casas» (1120); segundo, Teodosia y don Rafael, acompañados de Calvete, criado de don Rafael, caminan hasta encontrarse con los pasajeros atados a los árboles por unos bandoleros a dos leguas de Igualada, de donde pasan a una venta de esta ciudad y en la cual se descubre la identificación de Leocadia; los hechos aquí tienen lugar también en diversos sitios: en dos cuartos de dormir el de Teodosia y Rafael y en el que pasó la noche Leocadia-, el comedor y el balcón donde Leocadia cuenta sus experiencias con Marco Antonio; tercero, los cuatro personajes se dirigen hacia Barcelona, donde llegan al anochecer después de un largo viaje y en donde la acción se reparte entre la playa, las calles - Rafael «andaba como loco por las calles buscando» a Leocadia (p. 1136) - , las galeras y la casa de don Sancho de Cardo-

4 Joaquin Casalduero, Sentido y forma de las «Novelas ejemplares», 2nd. edición. Madrid, Editorial Gredos, 1969, 1964, p. 204. 
na; cuarto, de Barcelona, las dos parejas desposadas, acompañadas de Calvete, van a Santiago de Galicia, pero habiendo pasado antes tres días en Montserrat; y finalmente, de Galicia se nos traslada a Andalucía otra vez, dando así una forma circular a la novela.

Se podria afirmar además que, aunque es interesante el criterio de Casalduero, con ello no se explica satisfactoriamente la diversidad y semejanza al mismo tiempo de las cuestiones de amor sobre las que la armazón de la novela descansa -1, el amor de Marco Antonio y Teodosia; 2, el de Leocadia y Marco Antonio; y 3, el de Rafael y Leocadia - ni se presta para seguir el desarrollo de la fábula. Aqui se sugiere que la comprensión de Las dos doncellas, teniendo en cuenta su sentido y los diferentes recursos artísticos utilizados en el novelar del embrollo de la promesa matrimonial de Marco Antonio, exige verla como una realidad pictórica dividida en tres partes principales, las cuales encierran tres centros tectónicos y cuyas líneas demarcatorias son bastante semidefinidas y a veces se entrecruzan. De estos tres núcleos fundamentales, concebidos no matemáticamente y que corresponden a los relatos de Teodosia y Leocadia de sus respectivas experiencias amorosas con Marco Antonio y a la declaración de amor de don Rafael, dos se encuentran puestos de una forma recontada en la primera parte de la obra y, el tercero, en la parte central.

La primera sección principal termina con la introducción del amor de Rafael hacia Leocadia y el hallazgo de Marco Antonio en Barcelona. La segunda parte principal corre desde este punto hasta que los dos matrimonios se llevan a cabo en la misma ciudad: el de Marco Antonio con Teodosia y el de don Rafael con Leocadia, lo que significa que la tercera cuestión de amor se encuentra en esta partición. Y, finalmente, la tercera partición principal comprende desde aquí hasta que se completa el argumento o sea hasta que el padre de Marco Antonio hace *celebrar... las bodas de su hijo y Teodosia y la de don Rafael y Leocadia» (p. 1140) en Andalucía. Con ello, empero, no se acaba la obra, sino que ésta continúa por más de un párrafo, que funciona como marco de la tela del retablo y de lo cual se hablará más adelante.

Las regiones de Andalucía y Cataluna son los escenarios de la acción de la primera parte. En Cataluña tiene lugar la segunda; y la tercera en Cataluna, Galicia y Andalucía, tres lugares que sirven para formar espacialmente un magnífico viaje triangular, siendo Cataluna la que une los tres fragmentos estructurales. En uno se plantea la búsqueda de la solución del enredo ocasionado antes de la acción de la novela por la palabra de casamiento dada por Marco Antonio tanto a Teodosia como a Leocadia, trayendo como consecuencia dos niveles de realidad: en uno la pérdida del honor, en 
el otro la ausencia de seducción o conservación del honor. En el segundo fragmento se resuelve dicho laberinto, pero sólo en un plano personal por medio de los dos connubios; y en el tercero se rectifica, al retornar los personajes principales a sus respectivas parentelas, el deshonor y la deshonra en un plano familiar y social o, si se quiere, nacional. Se dice nacional porque la obra incluye a España en sus tres principales ángulos geográficos: Andalucía, Cataluña, Galicia.

En primer lugar, don Rafael y el hipotético lector escuchamos en la primera parte el asunto amoroso de Teodosia y Marco Antonio, relatado por aquélla en la mencionada venta de Castilblanco, que está en Andalucía; en segundo lugar, Leocadia nos cuenta sus amoríos con Marco Antonio al lector y a Teodosia, quien a su vez informa de ello a don Rafael en una venta de Igualada, que está en Cataluna.

En la segunda división oímos la confesión de Marco Antonio por la que se lleva a cabo el rechazo de Leocadia (por Marco Antonio) en favor de Teodosia y la materialización de la cuestión amorosa de don Rafael y Leocadia. Esta declaración de amor acontece en las playas de Barcelona y su desarrollo tiene lugar en el presente temporal de la acción principal de la novela y no es una disposición efectuada antes de dicha acción principal, como ocurre con las otras cuestiones de amor. Por otro lado, este tercer asunto amoroso es un problema que el lector ya lo había percibido en germen en la primera partición de la obra, pues alli nació el amor de don Rafael hacia Leocadia. Es más, de ello sabemos con certeza don Rafael, el narrador y el presunto lector en el curso de la acción, más los otros personajes principales, con excepción de Leocadia -se dice con excepción de Leocadia, porque ésta ya presentía que don Rafael se había enamorado de ella en la primera parte estructural-, llegarán a enterarse al final de esta segunda parte estructural de la obra.

Y, finalmente, en la tercera parte principal se cumple la romería prometida por Marco Antonio en la sección anterior (la segunda parte) de ir a Santiago de Galicia primero; segundo, presenciamos, por una parte, el caballeresco desafío de los padres de los personajes principales en Andalucía y, por otra, el reencuentro lleno de júbilo de los padres con los hijos y de éstos con sus pueblos. Esta parte estructural se parece a la primera en cuanto que en ambas hay viajes: la búsqueda y el retorno, los cuales encierran el hallazgo o la parte central de la novela. En la búsqueda se hace actuar a tres personajes principales con posibilidades de convertirse en parejas, en el retorno los personajes funcionan ya como parejas o desposados. 


\section{Perspectiva pictórica}

Que Las dos doncellas es una transposición artística pictórica, puede fundamentarse, además de lo ya apuntado, desde la perspectiva temporal. En la primera línea el narrador nos sitúa en un tiempo presente - «cinco leguas de la ciudad de Sevilla está (lo subrayado es mío) un lugar que se llama Castilblanco» (p. 1119) - y al final, una vez completado el sentido argumental, forma una trayectoria desde el pasado de los acontecimientos hasta el presente o sea hasta el solemne «hoy» desde el cual está contado: «hizo celebrar el padre de Marco Antonio las bodas de su hijo y Teodosia y las de don Rafael y Leocadia, los cuales, luengos y felices años vivieron en compañía de sus esposas, dejando de sí ilustre generación y descendencia, que hasta hoy dura (el subrayado es mío) en estos lugares» (p. 1140) ${ }^{5}$. Lo que Cervantes está haciendo aquí es encerrar con este «hoy» y el tiempo presente del comienzo de la novela una narración en el pasado, la cual incluye a su vez otras narraciones en el pretérito, que nos trasladan a pasados remotos y a otros más cercanos del relato principal.

La función de dichos relatos es aclarar las razones que movieron a actuar a los protagonistas en el pasado - anterior a la narra-

5 De las Novelas ejemplares, son cinco en las que el narrador conecta los acontecimientos pasados hasta el «hoy» desde el cual está narrando, aunque de una manera diferente en cada una: La española inglesa, La ilustre fregona, El amante liberal, La fuerza de la sangre y Las dos doncellas. En la primera, Recaredo e Isabela aún viven en el instante en que el narrador pone punto final a la acción de su novela; en la segunda ocurre lo mismo, pero con diferente función: en el caso de La ilustre fregona sirve para crear dos niveles de realidad y con lo que parece intensificarse la impresión de la existencia de dos novelas; o sea que Constanza aaún vive en compaña de su buen mozo de mesón», sin acondarse de su vida pasada y sin hijos (como sucede con Recaredo e Isabela), mientras que Carriazo, cuyos tres hijos ahoy están todos estudiando en Salamanca», no puede desprenderse de su pasado. En El amante liberal y en Las dos doncellas, aunque los protagonistas parecen no vivir ya, se habla de su descendencia que aún existe: «la fama de Ricardo... se extendió por todos los (términos) de Italia... y aún hasta hoy dura en los muchos hijos que tuvo en Leonisa* (p. 987) y don Rafael y Marco Antonio aluengos y felices años vivieron en companía de sus esposas, dejando de si ilustre generación y descendencia, que hasta hoy dura en estos lugares... de Andalucia» (p. 1140). En cambio, en La fuerza de la sangre no sólo se sugiere que los dos protagonistas aún viven sino que se habla de hijos y nietos: «quedó toda la casa sepultada en silencio, en el cual no quedaria la verdad de este cuento, pues no lo consentirán los muchos hijos y la ilustre descendencia que en Toledo dejaron, y ahora viven, estos dos venturosos desposados, que muchos y felices anos gozaron de si mismos, de sus hijos y de sus nietos» (p. 1064). Además, en La fuerze de la sangre Cervantes parece poner más énfasis en lo vendadero que en lo histórico del cuento y tanto en esta novela como en El amante liberal el ahoy», desde el cual se cuenta la historia verdadera, está mucho más cercano al final de lo novelado que en las otras tres. 
ción principal-, mantener en suspenso el paradero de Marco Antonio, de quien se decía que se había marchado para Italia, y unir unos cuentos a otros, aunando así, como ya se apunto ${ }^{6}$, las tres cuestiones de amor ${ }^{7}$ sobre las que la obra gravita (1, el amor de Teodosia y Marco Antonio; 2, el de Leocadia y Marco Antonio; y 3, el de don Rafael y Leocadia). Esta tercera cuestión amorosa o sea el amor de don Rafael y Leocadia, sin embargo, aunque cae dentro del montaje de la novela, no forma parte en realidad de su fábula, puesto que ésta trata del cumplimiento de la palabra de casamiento dada por Marco Antonio, ilustre y rico caballero de Andalucía, a dos doncellas ${ }^{8}$ principales - Teodosia y Leocadia- del mismo lugar que aquél. Por otro lado, este tercer problema amoroso se plantea muy entrada ya la narración y formando parte del relato primario, o sea unos diez días después de la entrega de la desdichada Teodosia a Marco Antonio.

El primer marco de la tela del lienzo, la cual muestra desde la deshonra y desorientación hacia la restauración de la honra mediante el matrimonio y la reunión familiar, se divide en dos escenas. En una se recalca en que hay algo oculto en todo lo que acaece; en la otra se pone énfasis en la curiosidad, todo lo cual sirve para mantener el interés del lector. Dentro de la primera escena está la llegada de un jinete que entra en una venta de las muchas que Castilblanco tiene. Después de apearse de su «hermoso cuartago extranjero» y de haberse «desabrochado muy aprisa los botones del pecho», da «manifiesto indicio de desmayarse». La muy caritativa huéspeda acude en su ayuda y lo hace volver en sí. Preocupado de haber sido visto con la blusa desabrochada, se vuelve a botonar apresuradamente. El inquieto jinete contrata la única habitación de dos Camas que quedaba desocupada, pagando por los dos lechos, $y$, luego de retirarse a ella sin cenar, cierra tras sí la puerta con llave, arrimándola además con sillas, para que nadie le molestase. Y apenas se encierra, admirados por la extraordinaria hermosura del supuesto caballero, «se juntaron a consejo el huésped y la huéspeda, y el mozo que daba la cebada (al cuartago) y otros dos

- Ver más adelante sobre las tres cuestiones de amor.

7 JENNIFFER THOMPSON afirma que cuatro cuestiones de amor forman la base de esta novela, ver «The Structure of Cervantes' Las dos doncellas», Bulletin of Hispanic Studies, XL, 1963, pp. 145-147.

8 ROBerr PIIUso afirma que una sola de las dos muchachas en Las dos doncellas es doncella y, por ende, el título es incorrecto. Vid. Amor, matrimonio y honra de Cervantes. New York, Las Americas Publishing Co., 1967, p. 23. Para mi Cervantes no se ha equivocado y no veo tal incorrección, puesto que dentro de la obra la palabra doncella viene usada con el sentido de mozuela o joven; además la obra trata de dos doncellas, de las cuales una pierde su honor y su honra, y la otra, aunque no compromete su honor, pierde también su honra. 
vecinos que acaso alli se hallaron» (p. 1120) para encomiar la belleza y gallarda disposición del recién llegado y discutir de su posible edad, resolviendo «que tendría de dieciséis a diecisiete años» (p. 1120). Nótese lo impreciso y oculto en cuanto al tono y a lo conceptual de la frase: al muchacho le «había pesado de que así le hubiesen visto" (con el pecho desabrochado) (p. 1120), no quiere que nadie le ayude, no acepta la cena que la huéspeda le ofrece, contrata las dos camas de la única habitación disponible y, luego de encerrarse en ella, asegura la puerta con llave y con dos sillas.

Poco después llega otro joven de «poca más edad que el primero y no de menor gallardía» (p. 1120), con lo que se inicia la segunda escena. Habiendo entrado en coloquio con la huéspeda, ésta le dijo que no se apease del caballo porque no tenía lecho para alquiler, ya que las dos camas que restaban habían sido contratadas por un mozo requetelindo. Claro está, las sin par alabanzas que aquélla hace de éste despierta en el segundo jinete cierta curiosidad de verlo: «-Ten aquí, mozo - dijo a esta razón el caballero-, que aunque duerma en el suelo tengo de ver hombre tan alabado» (p. 1120). Y, luego de bajarse de su caballo, pide algo de comer y al momento se le acerca un alguacil parlanchín, quien le echa una sarta de preguntas sobre la corte y las guerras de Flandes, a las cuales el caballero guarda silencio. Por otro lado, mientras el jinete come y calla, se reanudan de lance en lance los elogios del muchacho encerrado, lo cual, como es de esperar, intensifica la curiosidad del segundo jinete por verlo, hasta tal punto que «rogó al mesonero hiciese de modo cómo él entrase a dormir en la otra cama, y le daría un escudo de oro» (p. 1121).

Concedida dicha petición, «puesto que la codicia del dinero acabó con la voluntad del mesonero por dársela» ( $p$. 1121), conciertan en hacer de la realidad una cosa que no es: deciden tocar la puerta en nombre de la justicia. El encargado de llevar a cabo el plan es precisamente el alguacil -Cervantes parece aliviar así el convenio concertado o parece disfrazar la mentira-, y a quien, claro está, el jinete encerrado tuvo que abrirle tal puerta. Luego que el truco dio frutos, el jinete segundo, pidiendo perdón al primero, se fue a acostar de una forma decidida y sin reparos en el lecho desocupado. El otro supuesto mozuelo, a su vez, sin responder palabra alguna y sin dejarse ver el rostro, se acuesta en la otra cama «vuelta la cara a la pared» (1121), para dormir. Aqui Cervantes ciertamente se esfuerza en presentar a los dos jinetes, unidos por el espacio, la misma habitación, y en las tinieblas, en relación a una doble simulación: el segundo jinete, cuyo nombre no se sabrá hasta despés de ser expuesta la primera cuestión de amor, lleva en su conciencia la aceptación del truco del alguacil, quien había sugerido decir al to- 
car la puerta que por orden del alcalde venía a aposentarlo en el mesón; y el primer jinete también disimula al pretender dormir y ser otra persona que Teodosia. Y, finalmente, se cierra este primer relato de amor con la pintura del escenario -en el que el primer relato de amor se lleva a cabo- y a veces en forma de contraste haciendo eco a lo que sirve de base estructural en El celoso extremeño, es decir el contraste de lo tranquilo y pesado del mundo exterior y de los elementos cósmicos con la perturbación e intranquilidad interior y psicológica del primer jinete: «eran las noches de las perezosas y largas de diciembre y el frío y el cansancio del camino forzaban a procurar pasarlas con reposo; pero como no lo tenía el huésped primero, a poco más de la media noche comenzó a suspirar tan amargamente, que con cada suspiro parecía despedírsele el almax (p. 1121).

El segundo marco de la obra contiene dos secciones menos definidas que las del primer cerco y dentro de un tono alegre y de bienestar, elementos que contrastan con el aspecto de preocupación e intranquilidad del primer marco. En una sección se insiste en el aspecto moral de la historia, al mismo tiempo que se ruega comprensión en cuanto al comportamiento de las dos doncellas; en la otra sección, después de decirnos de lo afortunado que fue Calvete, el mozo de mulas, debido a las dádivas que le dieron los desposados, Cervantes de una forma similar a lo que hace en La gitanilla y La ilustre fregona - aunque no idéntica, artísticamente hablando-, hace que los poetas literaturicen los acontecimientos del cuento novelado: «los poetas de aquél tiempo tuvieron ocasión donde emplear sus plumas exagerando la hermosura y los sucesos de las dos tan atrevidas cuanto honestas doncellas, sujeto de este extraño suceso» (p. 1140) 9 .

El narrador, ya desde la primera sección de este segundo marco, nos proyecta desde el pasado de los acontecimientos hasta el tiempo presente, desde el cual está relatando. Se hace referencia de igual modo a la ilustre generación y descendencia que los protagonistas habían dejado: «luengos y felices años vivieron (Marco Anto-

9 Es verdad que Cervantes hace que la historia novelada sea literaturizada dentro de la narración en La gitanilla, Las dos doncellas y La ilustre fregona, pero con gran diferencia: en La gitanilla los poetas de la ciudad y el narrador parecen estar presenciando los acontecimientos, en La ilustre fregona Costanza parece estar en los poemas aún en vida y en Las dos doncellas da la impresión de que los poetas están muy distantes del tiempo desde el cual el narrador está contando. Además, la literaturización por los poetas en Las dos doncellas está mucho más al final de la novela que en las otras dos obras. Todo esto explica o apoya lo que Cervantes reseña en su prólogo a las Novelas ejemplares: ala individualidad de cada una como la unidad de todas ellas» (p. 290). 
nio y Rafael) ${ }^{10}$ en compañía de sus esposas, dejando de sí ilustre generación y descendencia, que hasta hoy dura (el subrayado es mío) en estos dos lugares que son de los mejores de Andalucía» (p. 1140). La insistencia en lo moral de la historia, que se reduce a la opinión pública o al tema cultural español del qué dirán, se percibe al afirmar Cervantes que «si no se nombran (los pueblos), es por guardar el decoro a las dos doncellas, a quien quizá las lenguas maldicientes o neciamente escrupulosas les harán cargo de la ligereza de sus deseos y del súbito mudar de traje» (p. 1140). Cervantes aquí también, preocupado por la reputación de la persona y afirmando lo humano en la conducta de las dos doncellas, ruega que nadie se arroje «a vituperar semejantes libertades hasta que miren en si si alguna vez han sido tocados de estas que llaman flechas de Cupido, que, en efecto, es una fuerza, así se puede llamar, incontrastable, que hace el apetito a la razón» (p. 1140). En realidad, lo que Cervantes parece querer hacer en las últimas líneas de la obra, como sugiere Casalduero, es «elevar la realidad a un plano heroico, pero (como) sabe que no es fácil de alcanzar, ...exige la comprensión de la debilidad humana, la cual no será censurada por los hombres fuertes y con vocación para el heroismo sino por los pusilánimes»"

\section{Planos de la narración y las tres cuestiones de amor}

Mucho se ha criticado la supuesta innecesaria duplicación de las dos heroínas en Las dos doncellas hasta tal punto de afirmar que «son tan semejantes entre sí, que podrían trocar sus papeles y nombres respectivos sin detrimento de la trama» ${ }^{12}$, poniendo en duda con ello la capacidad artística del ingenio de Cervantes. Que uno no acepte el valor estético de la obra por gustos personales o preferencias es admisible, pero insinuar que Cervantes no sabía lo que estaba haciendo al hacer reaccionar a las dos doncellas de una manera similar - no idéntica - ante la fementida posición amorosa de Marco Antonio supone no haber entendido el prop6sito artístico del autor. Que yo sepa, Jeniffer Thompson es la única que ha tratado

10 RodRiguez-Luis se equivoca al negar que Cervantes menciona los apellidos de los personajes (op. cit., p. 225): «con tal propósito es que, aunque no dice los apellidos de los personajes, se guarda de mencionar el nombre de los dos lugares de Andalucía de donde proceden sus personajes». Es verdad que Cervantes deja de decir los nombres de los lugares de nacimiento de los personajes, pero los apellidos si los nombra: Marco Antonio Adorno, hijo de don Leonardo Adorno (p. 1125), Leocadia de Cárdenas (p. 1125) y Rafael de Villavicencio (p. 1138).

"J. Casalduero, Sentido y forma de las «Novelas ejemplares», op. cit., p. 211.

12 A. G. DE Amezón y MAyo, Cervantes, creador de la novela corta española. Madrid, C.S.I.C., 1958, vol. II, p. 347. 
de dar respuesta a dicho problema, llegando a conclusiones esclarecedoras. Concordando con Thompson en cuanto a que athere is not an unnecessary duplication of roles» ${ }^{13}$, podríase añadir que las diferencias de Teodosia y Leocadia son más marcadas que las semejanzas. Estas últimas tienen que ver con la edad, el abandono de sus casas disfrazadas de hombre, el sacar dinero a sus nobles y ricos padres, la esperanza de que Marco Antonio cumpla su promesa matrimonial, la perspectiva confusa que cada una tiene de su infeliz situación presente y sus reacciones una vez descubierto el engaño de Marco Antonio. Teodosia afirma: «castigué mis cabellos, como si ellos tuvieran la culpa de mi yerro; martiricé mi rostro, por parecerme que él había dado toda la ocasión a mi desventura; maldije mi suerte, acusé mi presta determinación, derramé muchas e infinitas lágrimas» (p. 1123); y Leocadia por su parte dice: «maltraté mi rostro, arranqué mis cabellos, maldije mi suerten (p. 1130).

Las afinidades de Teodosia y Leocadia no son, empero, casuales; tienen una intención artística, sugerida ya en el título - Las dos doncellas-, puesto que se refieren a dos de las figuras principales de las tres cuestiones de amor que Cervantes se propone novelar. No sólo las similitudes de sus reacciones a su situación de engañadas, que vendrían a ser formas convencionales de expresar congoja, sino también las otras semejanzas obedecen al tema principal de la obra: la deshonra de las dos doncellas. Y además esas semejanzas obedecen al medio por el que se llega a esa deshonra, que vendría a ser el amor adornado del engaño; al estado psicológico presente de las dos chicas ${ }^{14}$; a la edad biológica de ambas muchachas, unque Cervantes usa, para darnos a concer, su técnica favorita de la imprecisión: el narrador refiriéndose a los años de Teodosia nos dice que los que estaban en la posada de Castilblanco «resolvieron que tendría de dieciséis a diecisiete años» (p. 1120); y en el caso de Leocadia afirma que don Rafael y Teodosia encontraron atado al tronco de una encina «un muchacho de edad, al parecer, de dieciséis años» (p. 1126). Y, por supuesto, muchas de las semejanzas, que rozan a veces las diferencias recíprocamente, tienen un propósito general artístico: la novelización de cuál de las dos heroínas tiene el mayor reclamo legal, emocional, amoroso y social hacia Marco Antonio.

Puede afirmarse, por otra parte, que con las analogías y disimilitudes Cervantes parece estar creando tres niveles de situaciones amorosas de forma intususcepcional y no yuxtaposicional. Estos tres grados novelados de existencia, que se entrecruzan y que a veces se

13 JeNNIfPer ThOMPSON, op. cit., p. 150.

14 Psicológicamente reaccionan de una forma similar porque las dos habian sido engañadas usando el poder del amor como motivo. 
rozan, no excluyen, por supuesto, otras realidades unidas por lazos refractarios y similares, entre los cuales están el pasado -los amores de las dos doncellas-, el presente - el desenredo de aquellos amores y el desarrollo del amor de don Rafael- y el futuro - la actualización de la suerte amorosa de los personajes principales en el segundo marco de la tela del retablo. El primer plano tiene que ver con el caso de la mujer en el que, al ser presa de un embuste, se pierde el honor y la honra; el segundo con la dama en el que al ser engañada, pero sin perder el honor físicamente, se compromete la honra; y el tercero, a modo de solución, el de la mujer en el que, al ser rechazada por obligaciones legales, morales y psicológicas, se rectifica la honra. El que da el primer impulso para la existencia de estos tres ámbitos unos diez días antes de empezar la acción principal de la novela es Marco Antonio. Este crea con sus falsas promesas connubiales las dos primeras cuestiones de amor en el pasado. De ellas nos enteramos en el presente por los relatos de Teodosia y Leocadia, por lo que afirma el narrador y por la confesión de Marco Antonio.

La tercera cuestión amorosa (o sea los amorios de don Rafael y Leocadia) comienza unas veinticuatro horas después de empezada la acción principal de la novela. A diferencia de las dos primeras cuestiones de amor, que abarcan el pasado y el presente, el desarrollo de la tercera se lleva a cabo solamente en el tiempo presente. Además de que, organizacionalmente, las tres empiezan en la primera sección estructural, tienen una solución parcial en la segunda y completa en la tercera, cada uno de los centros tectónicos amorosos (o de amor) tiene lugar en un estado de reposo exterior (sin movimiento) que contrasta con el marcado desasosiego interior de los personajes. En el primer centro tectónico el oyente y el relator están recostados en sus camas respectivas, al mismo tiempo que el que cuenta se encuentra en gran turbación hasta tal punto que no duerme en toda la noche; esta desazón se intensifica al no entender Teodosia «a donde se encaminaban aquellas confusas razones» (p. 1124) que le ofrecía el que resulta siendo su hermano; $y$, claro está, similar trastorno le entra a don Rafael, al enterarse de que Marco Antonio había engañado y ultrajado a su hermana. El locutor y el oyente en el segundo centro tectónico amoroso están también inmóviles: los dos están apoyados de pechos a una barandilla de un balcón que da a la calle, mientras ambos se encuentran intranquilos: Teodosia por su curiosidad $y$, luego de escuchar lo de la promesa que Marco Antonio habia hecho de venir a gozar a Leocadia, por la pestilencia de los celos; Leocadia se encuentra de igual modo inquieta por los deseos de encontrar al defraudador Marco Antonio y a su enemiga Teodosia, quien le está escuchando 
agitada, y con el sentimiento de haber sido engañada. $Y$ en el tercer centro amoroso los arrebatos tanto de Leocadia como de don Rafael contrastan con el «sosegado mar» que los escucha, con la quietud de los «estrellados cielos» que los cubren y con la inmovilidad, aunque sugerida, de los dos amantes durante la declaración de amor. Todo esto no significa, empero, que una cuestión amorosa pueda anularse sin afectar la existencia de la otra; al contrario, una está tan pendiente de la otra que, si se omitiera una o se trocara la función de un personaje por la del otro ${ }^{15}$, la otra no tendría razón de ser ni artísticamente ni en el sentido moral propuesto por Cervantes ${ }^{16}$, como veremos al hablar del sentido de la obra.

Según el aspecto temporal, el lector se entera primero del amor de Marco Antonio y Teodosia; después, del de Leocadia y Marco Antonio; y tercero del de don Rafael y Leocadia. Contrario al pasado caso amoroso de ésta o sea Leocadia, Cervantes empieza a darnos a conocer la amorosa situación laberíntica de Teodosia por medio de un doloroso monólogo, que por el tono recuerda el de Ricardo al comenzar la acción de El amante liberal y el de Leocadia luego de haber sido ultrajada villanamente por Rodolfo en La fuerza de la Sangre. Por ese triste soliloquio que sirve al mismo tiempo para empezar a revelar el misterio de Teodosia al hipotético lector y don Rafael, se hace referencia a un doble aspecto en forma de contraste: uno positivo y otro negativo. La falta de experiencia, aludida por Teodosia, apunta hacia lo primero o hacia la falta de culpabilidad; y, a lo segundo, el haber dado rienda suelta a sus deseos o sea la presencia de culpabilidad: «...ay de mí una mil veces, que tan rienda suelta me dejé llevar de mis deseos! ¿No soy yo la que tomo el cuchillo en mis manos, con que corté y eché por tierra mi crédito, con el que de mi valor tenían mis ancianos padres?» (p. 1121). Con lo primero Cervantes parece estar disminuyendo o purificando, si se quiere, la gravedad del actuar de Teodosia; y con lo segundo la hace responsable con repercusiones sociales, ya que a través de ello se puntualiza el haber atropellado los «respetos de (sus) honrados padres y parientes» (p. 1121) y cuán poco supo apreciar la honra.

Los amores de don Rafael y Leocadia duran unas 24 horas: desde que a don Rafael «se le abrasó el corazón con sus amores» (p. 1131), o sea empezando unas 24 horas después de haber comenzado

15 Para RUTh El SAFrar Loocadio ahas no independent meaning in the story, being representative of Teodosia's repressed active self, (op. cit., p. 116).

16 Formalmente el cambio de los papeles de Leocadia y Teodosia afectarfa la trama de la obra no s6lo en el plano artístico, sino también en el plano moral. En este Teodosia perdio de facto su honor para lo cual consintio voluntariamente. Leocadia, en cambio, no fue seducida, aunque quiso serlo. 
la acción principal de la novela hasta que celebraron el «nocturno y nuevo desposorio» a solas en las playas de Barcelona. En el tiempo presente, el caso amoroso de Teodosia y Marco Antonio tiene una existencia de unas $\mathbf{4 8}$ horas: desde el principio de la obra hasta su unión matrimonial por manos del clérigo, al final de la segunda parte estructural; y el amor de Leocadia y Marco Antonio corre desde la introducción de ésta en la novela hasta que es rechazada por Marco Antonio, o sea que tiene un transcurso temporal de unas 24 horas.

Formalmente Teodosia y Marco Antonio aparecen como en dos polos opuestos -el defraudador y la defraudada - al mismo tiempo que son los que dan volumen a la obra: Teodosia por ser la figura principal de la redención de Marco Antonio; éste por ser en quien las esperanzas y temeridades de los otros personajes se centran hasta muy entrada la narración. A Marco Antonio, quien empieza a actuar propiamente en la segunda parte estructural de la obra, lo conocemos en la primera parte por lo que los otros personajes dicen de él. Los otros tres personajes, en cambio actúan, como quedó sugerido anteriormente, en la primera sección de un modo específico e incambiable: don Rafael de oyente y Teodosia de relatora primero; después ésta pasa a ser la oyente y Leocadia es la relatora, quien a su vez sirve para enlazar retrospectivamente las dos primeras cuestiones de amor en el tiempo presente de la acción principal y a ésta con los hechos ocurridos anteriormente a ella; don Rafael está ausente en la relación de Leocadia, de la cual le informa Teodosia.

No sólo es curioso que los exponentes de la innecesaria duplicación de las dos heroínas no hayan notado la razón de esas similitudes sino también las marcadas diferencias de sus situaciones presentes y de sus narraciones sobre sus respectivas aventuras amorosas con Marco Antonio. Leído el texto con cuidado, se descubre que Teodosia no fue la que inició su relación amorosa, sino el fementido Marco Antonio Adorno, mirándola una y muchas veces desde una ventana que frontera a la suya estaba y mandándole así «el alma por los ojos" (p. 1123). Al describir ella su encuentro amoroso, pone énfasis en los sentimientos y no en cómo se llegó a ello: «sin saber cómo me entregué en su poder a hurto de mis padres, ni tener otro testigo de mi desatino que un paje de Marco Antonio» (p. 1123). Después de haber perdido Teodosia la doncellez se vistió de hombre usando un vestido de camino de su hermano, sacó dinero, ensilló un cuartago de su padre y decidió dejar su casa una noche oscurísima con intención de ir a Salamanca ${ }^{17}$ donde se creía

17 No estamos de acuerdo con RUTH EL SAFPAR para quien aboth steal from their equally rich fathers and leave for Bancelonax (op. cit., p. 111). En realidad cada una de las doncellas deja su casa con rumbo diferente. 
que Marco Antonio estaba» (p. 1123). El propósito de su salida fue, pues, de ir en busca de aquél para hacerle cumplir su promesa matrimonial o para matarle en defensa de su honor, si desmintiera el haberla gozado y se negara a reconocer aquella sortija de diamante que le había dado y en la que aparecía que «es Marco Antonio esposo de Teodosiax (p. 1123).

En la narración de Leocadia, en cambio, se nota que en su relación con Marco Antonio fue más insolente que Teodosia: ella tomó la iniciativa y había decidido de antemano que aquél era el hombre que deseaba para esposo por su "gentileza», "discreción», la alta calidad de su linaje y «la mucha cantidad de los bienes que llaman de fortuna que su padre tenía» (p. 1129). Creyendo que todo ello me iba a traer felicidad le comencé a «mirar con más cuidado, y debió de ser, sin duda, con más descuido, pues él vino a caer en que yo le miraba», dice Leocadia (p. 1129). De una forma similar a Teodosia, Leocadia recalca que, después de haber hecho «firmes y cristianos juramentos de ser" aquél su esposo, se ofreció a él para que hiciese lo que quisiera; pero, contraria a Teodosia, puesto que ésta no es la que exige prueba alguna, Leocadia para asegurarse de no ser engañada, hace que le escribiese una cédula con su firma. Al describir el arreglado encuentro de amor, Leocadia no hace sobresalir los sentimientos, como ocurre en la narración de Teodosia, sino el modo de llegar a él: «recibida la cédula» - dice Leocadia-, «di traza cómo una noche viniese de su lugar al mío y entrase por las paredes de un jardín a mi aposento, donde sin sobresalto alguno podía coger el fruto que para él solo estaba destinado» (p. 1129).

Leocadia, por supuesto, es engañada, ya que Marco Antonio no se presenta a la cita arreglada y añorada por aquélla. Cervantes, claro está, no se detiene a analizar las razones que condujeron a Marco Antonio a no cumplir su palabra, sino que describe la aflicción de Leocadia al enterarse ésta, a los ocho días de haber sido engañada, que el fementido joven había robado a una «doncella de extremada hermosura y de rara discreción» (p. 1129), llamada Teodosia, y se habian ido a otro lugar. Los sentimientos que se recalcan, contrarios a la situación de Teodosia, son la envidia y los celos, los cuales hacen que la celosa muchacha se maltratase el rostro, se arrancase los cabellos, dejase su casa y, dominada de venganza, se fuese en busca de Teodosia ${ }^{18}$. Para llevar a cabo estos

18 Por supuesto, hay que apuntar que el comportamiento de Leocadia tiene un matiz de castigo, ya que lo que más sentia era no poder hacer esos asacrificios a todas horas, por la forzosa presencia de (sus) padres» (p. 1130). Este tono de castigo está ausente en el caso de Teodosia. ¿Y cuál será la intención de Cervantes a este respecto? Se cree que Cervantes quiere dejarnos a entender con ello que en 
sentimientos rencorosos, Leocadia hurta los vestidos de un paje de su padre y a éste mucha cantidad de dineros ${ }^{19}$. Cubierta con la capa negra de su padre sale a pie llegando a Osuna, donde se acomoda en un carro hasta Sevilla y en donde compra otros vestidos y una mula para ir a Barcelona.

Caracterológicamente las dos heroínas aparecen en el tiempo presente de la acción en un estado de desdicha, aunque el de Leocadia en un nivel menos definido porque no sabe si atribuirlo a la "fortuna", o al "amor", o a su "poca advertencia». Teodosia, en cambio, culpa su infelicidad a su inadvertencia, locura y al creer "palabras compuestas y afeitadas de fementidos hombres" (p. 1122). De las dos, Teodosia aparece como la de más recato, recogimiento, obediencia y sumisión; por eso, lo que le fatiga más y de lo que tiene más miedo es que le sigan sus padres y la hallen por los vestidos y el cuartago que trae. Es verdad que las dos narran sus historias a oyentes que resultan ser otros de los que se habían imaginado, pero hay diferencias drásticas en las motivaciones de sus actos: Leocadia se desenvuelve por los motivos de venganza y celos, Teodosia por querer recuperar su honor, hasta tal punto que el mismo amor que existió en ella pasa a un segundo plano.

A diferencia de la descripción de la hermosura de Teodosia, que es hecha por boca de los personajes secundarios, la de Leocadia está a cargo del narrador, lo que representa más alejamiento en cuanto a Teodosia por parte de Cervantes. En la delineación de Leocadia se percibe menos encubrimiento en cuanto a su identificación que en la de Teodosia, pues sus orejas horadadas y su mirar vergonzoso hacían sospechar "que debía ser mujer» (p. 1127); y para poner énfasis en lo ineficaz de su disfraz, Cervantes hace que don Rafael y Teodosia se den cuenta que está mintiendo en cuanto a su descendencia familiar. Si en la situación de Leocadia, antes de introducir su historia amorosa, se recalca la curiosidad por parte de Teodosia hacia aquélla y la progresiva confirmación de que era mujer y de que todo lo que decía era mentira, en el caso de Teodosia, a don Rafael se le pinta con un tono sensual, tocando los bordes del incesto tal como se percibe en La ilustre fregona: «y estuvo (don Rafael) muchas veces determinado de irse a la cama de la que creía ser mujer; y hubiéralo hecho si en aquella razón no le sintiera levantar» (p. 1122). Contrastando con la presentación de Teodosia, en la de Leocadia se nota un tono sensual y más festivo. A Leocadia la vemos más decidida y audaz que Teodosia, ya que a

el caso de Leocadia no existía amor verdadero $y$, por ende, pecó; mientras que en el caso de Teodosia sí hubo amor verdadero.

19 Es significativo que, al describir lo que Teodosia saca de su casa, Cervantes evita usar la palabra hurtar o robar. 
ésta se la muestra con miedo y con un semblante doloroso. Tanto a Teodosia y a don Rafael se los dibuja llenos de bondad y con un espiritu extremadamente compasivo hacia Leocadia, y a don Rafael de igual manera hacia Teodosia al principio de la novela.

\section{B. Sentido de la NOVEla}

Las dos doncellas, en relación a las otras novelas ejemplares cervantinas, en lo temático, motivos, subtemas y tonos, no es una excepción ${ }^{20}$. La obra, como la vida real, está entrelazada con una serie de temas, con sus respectivos tonos y matices, que podrían clasificarse en dos grupos principales y de los cuales mencionaremos algunos: los menos positivos y los más positivos ${ }^{21}$. Entre éstos vale mencionar la comprensión, la caridad, el arrepentimiento, la libre voluntad y el heroísmo. Hay perdón por parte de don Rafael hacia Teodosia, al contrario de lo que se imponía culturalmente en la época de Cervantes, ya que la muchacha esperaba venganza por parte de su hermano por la pérdida de su honor ${ }^{22}$ y lo curioso de la obra es que su tencera parte estructural contiene una pictórica presentación al aire libre de la lucha de los tres caballeros por medio de la cual se nos comunica el modo de pensar cervantino: el perdón de los errores humanos el cual es necesario para evitar consecuencias trágicas ${ }^{23}$. También podría decirse que Cervantes ter-

20 RUTH El SAFPAR afirma que ain the wide variety of types and accents and attitudes which competed for equal hearing in Cervantes's earlier works, there is in Las dos doncellas greater concentration on a single theme» (op. cit., p. 109).

21 En las obras de Cervants es difícil, si no imposible, dicotomizar entre lo bueno y lo malo. Esto es asi, porque para el pensar de Cervantes no existe lo bueno o lo malo, sino lo bueno y lo malo en una persona.

22 Casuldurro afirma que «Teodosia espera lo que la tradición literaria al parecer imponia, haciendo de esta manera resaltar más la conducta de su hermano, al cual, caunque la soltura de su atrevimiento le incitaba a venganza, las palabras tan tiernas y tan eficaces con que manifestaba su culpa le ablandaron de tal suerte las entrañas, que, con rostro agradable y semblante pacifico, la levantó del suelo, y la consolo lo mejor que pudo y supo, diciendole, entre otras razones, que por no hallar castigo igual a su locura lo suspendía por entonces» (palabras que aparecen en Las dos doncellas citadas por CASALDUERO, op. cit., p. 216). Al referirse al problema del honor de Leocadia en La fuerza de la sangre, A. G. DE AMEzÓ Y MAYo asevera: «el lector de las novelas de nuestro Siglo de Oro, todo aquel que conozca su ideologia y sus costumbres, al llegar a este punto del parlamento de Leocadia, podria temerse logicamente una reacción cruel y sangrienta por parte de su padrex (op. cit., p. 213).

23 Casuldurro ha llegado a conclusiones parecidas en cuanto a dicha escena por diferente método: ade esa perspectiva de arriba abajo, parece que se nos invita a comprender los errores humanos e impedir sus tragicas consecuencias» (op. cit., p. 219). 
mina esta obra de mucho acierto artístico pidiendo a los lectores comprensión de la debilidad humana y que no se arrojen a vituperar «libertades hasta que miren en si si alguna vez han sido tocados de estas que llaman flechas de Cupido, que, en efecto, en una fuerza, si así se puede llamar, incontrastable, que hace el apetito a la razón» (p. 1140).

En cuanto a la caridad basta decir que es practicada por don Rafael y Teodosia hacia Leocadia después de que es asaltada por los ladrones y por el caballero catalán al socorrer a los personajes principales en la pelea de la gente de las galeras con la de la ciudad. El arrepentimiento se nota en Teodosia al confesar su pecado a su hermano en larga, frigida y perezosa noche en la que empieza la acción de la novela como también en Marco Antonio al verse cerca de la muerte ${ }^{24}$. La libre voluntad no sólo se nota en el comportamiento de Teodosia sino también en el de Leocadia, ya que ambas se entregan a Marco Antonio voluntariamente, poniendo énfasis con ello en la responsabilidad individual en los actos humanos, pensamiento que recuerda lo que Preciosa decía en La gitanilla. Del heroísmo en Las dos doncellas ya lo apuntó acertadamente Casalduero al decir que, Cervantes en esta obra, «en lugar de contribuir a la formación del recurso dramático de pundonor, colabora en la creación del tipo de mujer socialmente heroicas ${ }^{25}$.

Entre los temas positivos podrian mencionarse la desesperación, la venganza, el temor, el egó́smo y los celos, los cuales, debido al modo en que vienen tratados, a veces no se pueden separar. Los celos fueron los responsables de que Leocadia perdiera la paciencia al oir que Teodosia, «doncella de extremada hermosura y de mucha discreción» (p. 1129) y a quien no conoce, se había ido con Marco Antonio. Teodosia ${ }^{26}$, por su parte, siente la pestilencia de los celos al escuchar que Marco Antonio había prometido gozar a Leocadia al ver que ésta tenía una «peregrina hermosura» y «una rara discreción» ${ }^{27}$. También se nota desesperación en Leocadia al

24 A. G. De Amezón y Mayo afirma que «Marco Antonio es un vulgar seductor, a quien impulsa tan sólo el apetito sensual; únicamente la visión de la muerte, que cree cercana le volverá la cordura, para acordarse entonces de que es caballero y está obligado a reparar la grave ofensa hecha a Teodosia en su honor (op. cit., p. 347).

25 Casalduero, op. cit., p. 217.

26 Don Rafael se hace dominar también de la pestilencia de los celos, puesto que el narrador afirma: «no se podrá contar buenamente los pensamientos que los dos hermanos llevaban ni con cuán diferentes ánimos los dos iban mirando a Loocadia, deséndole Teodosia la muerte; don Rafael, la vida; entrambos celosos y apasionados» (p. 1132).

27 JenNIPPER THOMPSON se hace una pregunta interesante en cuanto a los celos, pregunta que funciona, para esta comentarista, como la cuarta cuestión de 
ser rechazada por Marco Antonio en favor de Teodosia y en don Rafael al darse cuenta de que Leocadia ya no estaba a su lado en ese momento: «mas apenas había llegado (aquélla) a la calle, cuando don Rafael la echó de menos, y como si faltara el alma, preguntó por ella, y nadie supo dar razón dónde se había ido; y así, sin esperar más, desesperado salió a buscarla» (p. 1136).

Con relación al temor y venganza, ya se mencionó al hablar de las motivaciones que las dos doncellas tuvieron al emprender la búsqueda de Marco Antonio y al describir sus diferentes situaciones. El tema del egoísmo es mucho más difícil separarlo de los temas principales que sirven de medio para presentar el objetivo principal de la obra, del cual se hablará en seguida. Con todo, se puede decir que don Rafael, una vez que el amor se apodera de él, se hace dominar del indigno sentimiento de no interesarse por el destino de su hermana y de Marco Antonio, pues sólo se preocupaba de sus propios anhelos: el casarse con Leocadia. El hecho de que Marco Antonio no cumpla con su palabra matrimonial por irse a Italia en busca de su libertad juvenil bordea asimismo el egoísmo.

Todos los temas, tanto los menos positivos como los más positivos, están, sin embargo, en función de los temas del engaño, del amor y del honor, los cuales sirven para presentar el objetivo intentado por Cervantes: la rectificación de la deshonra individual, familiar y nacional mediante el matrimonio y la reunión con las parentelas de los desposados. La novela empieza con la presentación del estado confuso de Teodosia ocasionado por el engaño fundamental, el engaño de Marco Antonio de que iba a ser su esposo, decepción que desencadenará otros fraudes en varios niveles de realidad, no sólo en el tiempo pasado sino también en el presente de la acción principal. Así tenemos que don Rafael aún en el marco de la obra participa en el embrollo para entrar en el cuarto de Teodosia, sólo para descubrir lo que no esperaba: la verdad, proceso temático muy favorito en el Barroco español conocido con el nombre del engaño y el desengaño ${ }^{28}$.

amor de las cuatro cuestiones (para nosotros hay sólo tres cuestiones de amor) sobre las que la armazón de la novela descansa: "Who has the greater cause for jealousy, Leocadia who relies entirely on her imagination (which is influenced and distorted by this same jealousy) or Teodosia who has the object of her jealousy before her and appreciate her beauty and other virtues and at the same time let her imagination increase their worth» (op. cit., p. 147).

28 RUTH EL SAFFAR mantiene que athrough Marco Antonio's deception... both he and Teodosia discover the truth of their life, their mariage, the church, and society" (op. cit., p. 117). Se podría añadir que el engaño revestido de amor, aunque no es el último fin intentado por Cervantes, es el impulso que sirve de base para la armazón de la obra. 
La acción de la novela avanza. Nos enteramos de la pérdida de la virginidad de Teodosia y de los pormenores bajo los cuales se creó «el intrincado laberinto» (p. 1121). Se introduce a Leocadia, la segunda doncella, quien, desatada de lo que la habian atado los ladrones al tronco de una encina, identifica a su familia mintiendo y quien aparece en escena, como Teodosia, aparentando no ser mujer. Luego de rectificar su mentira en cuanto a su procedencia, nos cuenta los detalles de la suerte que tuvo con Marco Antonio y de cómo éste, después de haberla engañado, había desaparecido de su pueblo sin dejar rastro alguno. El engaño se siente, pues, en toda la obra en una variedad de matices y tonos y, sobre todo, sus consecuencias en varios planos, como el duelo que iba a llevarse a cabo entre los tres caballeros al regresar los protagonistas a sus respectivas casas, o el que don Rafael se enamorara de Leocadia.

El problema del amor es todavía mucho más complicado que el del engaño, puesto que aquél está revestido algunas veces de éste y existe en varios niveles, trayendo así resultados diferentes. Tanto Teodosia como Leocadia, como afirma Casalduero, «no son dos mujeres ideales que se presentan como norma viva de una conducta, pero tampoco son unos seres bajos y plebeyos, dominados por la lujuria y esclavos de los instintos. Estas dos doncellas han encontrado el amor y han caído bajo su imperio" ${ }^{29}$. Teodosia, como se dijo anteriormente, no sólo quiere perder su honor por amor, sino que de hecho lo pierde, mientras que Leocadia se queda simplemente en el querer; o sea que ambas son presa de la seducción por propia voluntad, pero sólo bajo la promesa de matrimonio. Esto explica el hecho de que Teodosia no culpe explícitamente a Marco Antonio ni a nadie de la pérdida de su virginidad y de su honra, sino a sí misma, «de lo cual se deriva que para Cervantes la seducción es tanto un acto físico como un acto espiritual» ${ }^{30}$.

El doble aspecto de la seducción exige aclarar un poco más la situación amorosa que existió entre los personajes principales, el nivel amoroso en que se desenvuelven y las razones por las que Cervantes decide poner dichos amores como base de esta novela. Por el relato de Teodosia sabemos que la criaron con mucho recogimiento y recato y que la primera vez que había visto a Marco Antonio no había sentido kotra cosa que fuese más de una complacencia de haberle visto» (p. 1122). Este agrado inicial se va profundizando poco a poco debido a las muchas veces que Marco Antonio la miraba desde su ventana, miradas que se convirtieron en pa-

\footnotetext{
29 Casalduero, op. cit., p. 211.

30 Robert Piluso, op. cit., p. 77.
} 
labras, deseos, promesas y terminando en la consumación de «la virtud que hasta entonces no había sido tocada» (p. 1123).

En el caso de Leocadia, en cambio, Marco Antonio parece que tenía más intimidad con el padre de ésta que con ella, ya que ambos se iban de caza al campo y a veces se quedaba en su «casa cinco o seis días... y aun parte de las noches» (p. 1129), y no hay indicación de que le prestara mucha atención a Leocadia. Además, aunque ésta era tan recogida y honesta como Teodosia, Marco Antonio le dice a Leocadia al final de la parte central de la obra que lo que hizo con ella fue por pasatiempo y por cumplir más con el deseo de ella que con el de él. A este respeco leamos las propias palabras de Marco Antonio: «confieso, hermosa Leocadia, que os quise bien y que me quisisteis, y juntamente con esto confieso que la cédula que os hice fue más por cumplir con vuestro deseo que con el mío; pero antes que la firmase, con muchos días, tenía entregada mi voluntad y mi alma a otra doncella del mismo lugar, que vos bien conocéis, llamada Teodosia, hija de tan nobles padres como los vuestros; y si a vos di cédula firmada de mi mano, a ella le di la mano firmada y acreditada con tales obras y testigos, que quedé imposibilitado de dar mi libertad a otra persona en el mundo. Los amores que con vos tuve fueron de pasatiempo, sin que de ellos alcanzase otra cosa sino las flores que vos sabéis, las cuales no os ofendieron ni pueden ofender en cosa alguna; lo que con Teodosia me pasó fue alcanzar el fruto que ella pudo darme y yo quise que me diese, con fe y seguro de ser su esposo, como lo soy» (p. 1135). De estos vocablos, del tono de las narraciones de las dos doncellas y del modo con que sus personalidades están delineadas, se puede concluir que el comportamiento de Leocadia cae dentro de lo más instintivo del amor ${ }^{31}$, mientras que el amor de Teodosia es el menos instintivo; segundo, en el caso de ésta y Marco Antonio existe reciprocidad amorosa, algo que falta en la relación con Leocadia, aunque las cualidades por las que ambas se sentían atraídas hacia Manco Antonio son similares: la gentileza, la rara discreción y cortesía, la calidad de su linaje y la mucha cantidad de bienes materiales.

Esas similitudes, en cambio, no anulan la individualidad funcional de cada doncella ni la doble promesa nupcial de que Cervantes hace uso para crear un argumento novelado en dos planos de realidad que se rozan: el de Leocadia en un marco que, aparentando ser legal, es únicamente emocional, social y amoroso; y el de

31 Hay que apuntar el extremado sensualismo en la historia de Leocadia, ausente en la de Tedosia: arecibida la célula, di traza cómo una noche viniese de su lugar al mío y entrase por las paredes de un jardín a mi aposento, donde sin sobresalto alguno podía coger el fruto que para el solo estaba destinado» (p. 1129). 
Teodosia en un nivel que, sin dejar de ser legal, psicológico, familiar y social, es realmente moral. En un plano tenemos a la mujer engañada, que pierde su honor y honra; en el otro, a la mujer que, aunque engañada, sin perder su honor, pierde su honra, dos planos que, de ninguna forma se pueden trocar ni ser anulados, si se quiere respetar el sentido que Cervantes quiso dar a esta obra de gran alcance artístico. En otros términos, Teodosia está en un plano que exige no sólo el cumplimiento de la promesa matrimonial dada por Marco Antonio y la rectificación de su honor perdido al entregarse al ingrato seductor, sino también la restauración de la honra familiar, ya que con dicho acto su familia quedó deshonrada: «mis padres son nobles y más que medianamente ricos, los cuales tuvieron un hijo y una hija, él para descanso y honra suya y ella para todo lo contrarion (p. 1122).

Por otra parte, tenemos el motivo amoroso de don Rafael. Este amor nace al enterarse don Rafael de la identidad de Leocadia y al contemplar que su hermosura era de una mujer y no de un hombre, como hasta entonces se imaginaba. Esta experiencia amorosa es mucho más corta que los otros dos amores. En realidad, el cortejo de esta tercera cuestión amorosa no dura mucho tiempo, puesto que desde que la conoce, lo cual tiene lugar en la primera parte estructural de la obra, hasta que se dan la mano en las playas de Barcelona hay un transcurso de apenas un día completo y parte de dos noches no consecutivas. Esto simplemente significa que, además de que Las dos doncellas está muy bien pensada y construida, la introducción de los amores de Leocadia y de don Rafael viene a funcionar como premio para éste ${ }^{32}$ de rectificación del enredo de la seducción de aquélla ocasionado por Marco Antonio. Sin esta tercera cuestión amorosa, Leocadia hubiera tenido como posibles alternativas, según las costumbres de la época de Cervantes, el convento, el suicidio, la vida pública o el matrimonio. Cervantes no permitió que escogiera el convento por la tan liberal y sensual personalidad de ella; tampoco hizo que se decidiera por el suicidio ni la vida pública, porque, como notó Piluso ${ }^{33}$, permitirle lo primero era muestra de cobardía, y lo segundo iba contra la bondad humana de Cervantes, y, por eso, hizo que se casara con don Rafael.

En Las dos doncellas se pone énfasis en el matrimonio como fuerza restitutiva del honor y de la honra; o sea como medio y no como fin en sí mismo. El connubio de las dos parejas, pues, está proyectado no sólo hacia lo social, sino también hacia lo religioso, dos

32 El connubio de Leocadia con don Rafael podrfa pensarse que viene a ser de premio para éste por la caridad, comprensión y ayuda que le prestó, sobre todo, a Teodosia.

33 Robert Piluso, op. cit., p. 46. 
sistemas que coexistían en el siglo XvI. Por eso la tercera parte estructural de Las dos doncellas, lo que recuerda el final de La española inglesa, termina, por una parte, con la visita que los recién desposados hacen al famoso monasterio de Montserrat y con la peregrinación a Santiago de Galicia. Esta romería viene a ser indudablemente como una acción de gracias y en cumplimiento de la promesa que Marco Antonio había hecho mientras estaba enfermo en la segunda parte de la obra. Por otro lado, las dos parejas, una vez santificadas por esa peregrinación religiosa, tienen que enfrentarse a la catastrófica consecuencia que produjo la doble promesa nupcial de Marco Antonio en el orden social: el duelo de los tres padres de los personajes principales, duelo que, claro está, fue evitado por la presencia de los hijos. Nótese a este respecto, la «gran cantidad de gente armada, de a pie y de a caballo, los cuales venían a defender al caballero de su lugar» (p. 1140), con lo que se quiere recalcar el aspecto social y, tal vez, nacional, afectados por los actos no laudatorios de Marco Antonio.

Y para terminar, se podría decir que todos los temas, subtemas y motivos, vienen hilvanados con el fin de presentar, en la primera parte estructural de la obra, la rectificación potencial de la deshonra; en la segunda, la restauración de la deshonra en un plano personal, psicológico y emocional; y en la tercera, la solución de la honra familiar, religiosa, moral y social. $\mathrm{O}$, vista la obra desde otro ángulo, se la podría ideografiar como una búsqueda, un encuentro y un retorno, a través del cual se van ajustando cabos sueltos o se van solucionando cosas no resueltas.

Eleodoro J. Febres. Indiana University at South Bend 